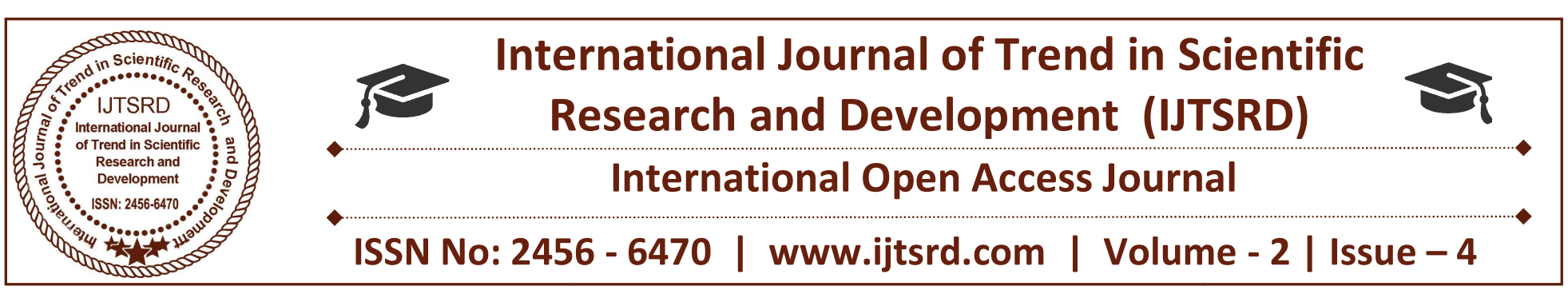

\title{
Performance Characteristics of A Variable Compression Ratio Engine using Transesterified Mahua Oil
}

\author{
D Pratyusha, S Venkateswara Sateesh V, T Ch Siva Reddy \\ Department of Mechanical Engineering, Sreenidhi Institute of Science \& Technology, \\ Hyderabad, Telangana State, India
}

\section{ABSTRACT}

The performance characteristics of a single-cylinder four-stroke variable compression ratio engine fueled with esterified Mahua oil were investigated. The suitability of esterified Mahua oil produced from seed of raw Mahua by transesterification process has been studied in variable compression ratio engine. Experiment has been conducted at various loads like 0 $\mathrm{kg}, 2 \mathrm{~kg}, 4 \mathrm{~kg}, 6 \mathrm{~kg}, 8 \mathrm{~kg}, 10 \mathrm{~kg}$, and $12 \mathrm{~kg}$ with engine speed of $1500 \mathrm{rpm}$ and at compression ratio's varies from 13:1 to $19: 1$. The impact of compression ratio depend on fuel consumption. The performance characteristics like Brake Thermal Efficiencies(BTH), Brake Specific Fuel Consumption(BSFC), Brake Specific Energy Consumption(BSEC) and Volumetric Efficiency(VE) are analyzed for Mahua oil in the variable compression ratio engine.

Keywords: Biodiesel; Esterified Mahua oil; Compression ratio; VCR engine; Transesterification

\section{INTRODUCTION}

The diesel engines are most widely used in automotives, construction equipment, marines and agriculture pumps. The diesel engine has higher thermal efficiency and durability when compared with other internal combustion (IC) engines. In agricultural based countries like India, China, and other south-east Asian countries, petroleum based diesel is not only widely used in the agriculture sector but also in transportation sector, accounting for more than $95 \%$ of the fossil fuel use [1]. At present, fossil fuels are playing a biggest role in the energy sector, but the deteriorating fossil fuel reserves, ever increasing the prices of crude oil that causing colossal influence on nations' economies [2,3]. The usage of fossil fuels has also perilous effect on environment and global warming effect [4]. Alternative fuels derived from biological sources such as plant based oils, waste oil and animal fat oil; provide a source for sustainable growth, u energy conservation, efficiency and environmental protection. Some of the alternative fuels explored are ethanol, biogas, vegetable oils and animal fat based oils, waste oil etc., [5].

Vegetable oil has become more attractive because of its environmental benefits and better quality exhaust emission. Vegetable oils are basically extracted from seeds through a series of processes involving drying, grinding, steaming, air-cooling, and oil extraction by hydraulic press and screening. The seeds contain 40$50 \%$ semi-drying oil, which is extractable by using hydraulic press (Clark et al. 1984). Though there are a variety of vegetable oils, their properties, which are of importance, lie within a fairly close range [8] Vegetable oils have cetane numbers of about 35-50 depending on their composition [6].

The authors have analyzed the combustion characteristics of single-cylinder four stroke direct injection variable compression ratio engine (ratios of 15:1 to 19:1) while using biodiesel blend as a fuel. It has been observed that the cylinder gas pressure, maximum rate of pressure rise, and heat release rate increase with higher ethanol concentration due to longer ignition delay. The exhaust gas temperature was found to be less [7]. The study also examined the 
fuel burning characteristics of the diesel-biodieselethanol blends under various compression ratios and loading conditions. The performance and emission tests have been carried out by using the stable fuel blends on a computerized variable compression ratio engine and compared with neat diesel [7]. From the investigation of the engine performance of Castor Methyl Ester (CME) and Potassium Hydroxide $(\mathrm{KOH})$ catalyst used in four-stroke single-cylinder variable compression ratio diesel engine at different loads, it was concluded that the lower blends of biodiesel increased the break thermal efficiency and reduced the fuel consumption.

\section{MATERIALS AND EXPERIMENTAL SECTION}

\subsection{FUEL PROPERTIES}

In this study, Mahua oil, which was extracted from dried Mahua, was collected from local vendor at Hyderabad, Telangana state, India and filtered to remove solid impurities in order to use it to perform the experimental analysis on performance characteristics of direct injection diesel engine.

The chemical properties of diesel fuel and Mahua oil were evaluated and presented in Table 1.

Table 1. Properties of Diesel and Mahua oil

\begin{tabular}{lccccc}
\hline \multicolumn{1}{c}{ Fuel Property } & Unit & $\begin{array}{c}\text { ASTM } \\
\text { Standard }\end{array}$ & Diesel & $\begin{array}{c}\text { Mahua } \\
\text { Oil }\end{array}$ \\
\hline \hline $\begin{array}{l}\text { Kinematic Viscosity } \\
40^{\circ} \mathrm{C}\end{array}$ & $\mathrm{C}$ & $\mathrm{Cst}$ & $\mathrm{D} 445$ & 5.37 & \\
Flash Point & ${ }^{0} \mathrm{C}$ & $\mathrm{D} 93$ & 165 & \\
Density @ $30^{\circ} \mathrm{C}$ Intern & $\mathrm{Kg} / \mathrm{m}^{3}$ & $\mathrm{D} 1298$ & 835 & 911 \\
Calorific Value & of Tre $\mathrm{MJ} / \mathrm{Kg}$ & Scientific & 43.5 & 39.1 \\
Cetane Number & $\mathrm{Re}$ & - & D613 & 52 & \\
\hline \hline
\end{tabular}

\subsection{EXPERIMENTAL SETUP}

Fig.1 shows the schematic diagram of the Variable Compression Ratio(VCR) engine experimental setup. The test engine used is a four-stroke variable compression ratio multi-fuel engine. The setup consists of single-cylinder four-stroke VCR (Variable Compression Ratio) diesel engine connected to eddy current dynamometer for loading. The compression ratio can be changed without stopping the engine and without altering the combustion chamber. A specially designed tilting cylinder block arrangement is used for varying the compression ratio. Provision is also made for interfacing airflow, fuel flow, temperatures, and load measurement. The setup has stand-alone panel box consisting of air box, two fuel tanks for duel fuel test, manometer, fuel measuring unit, transmitters for air and fuel flow measurements, and process indicator and engine indicator. Rotameters are provided for cooling water and calorimeter water flow measurement. The test engine was initially started with Esterified Mahua oil. After engine has reached the stabilized working condition at constant speed of
$1500 \mathrm{rpm}$, time for $10 \mathrm{cc}$ of fuel consumption was recorded for each applied load at different compression ratios in order to calculate the performance characteristics of DI diesel engine at different compression ratios.

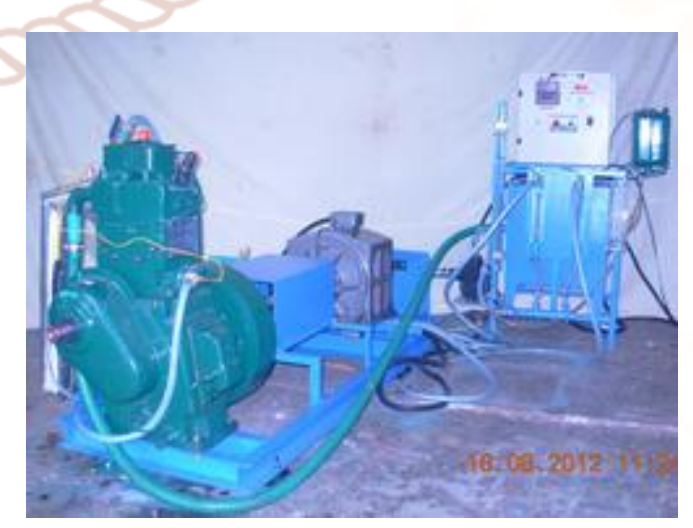

Fig. 1. 


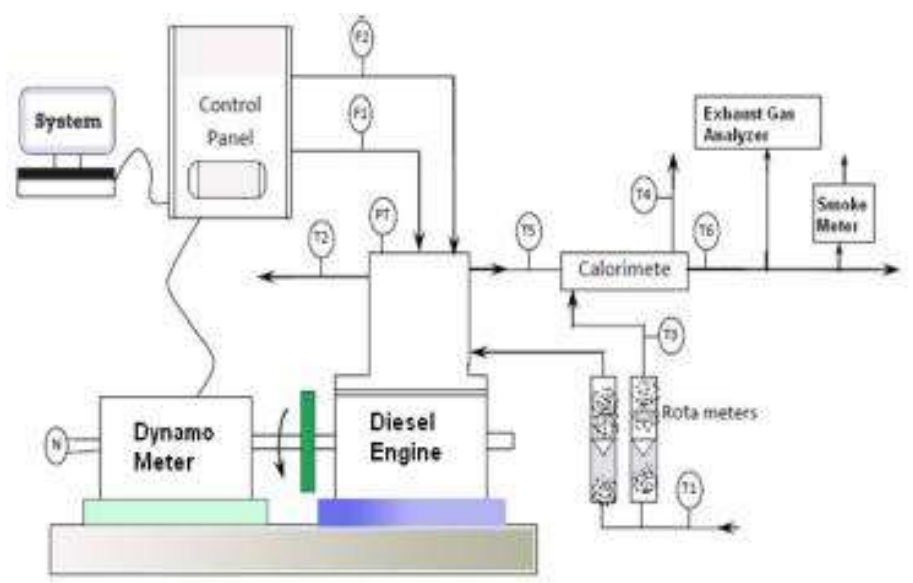

Fig.2. Schematic Diagram of Experimental Setup

\begin{tabular}{|c|l|c|l|}
\hline T1 & $\begin{array}{l}\text { Inlet water } \\
\text { temparature }\end{array}$ & P1 & Pressure transducer \\
\hline T2 & $\begin{array}{l}\text { Outlet engine } \\
\text { jacket water temp }\end{array}$ & F1 & $\begin{array}{l}\text { Air intake differential } \\
\text { pressure unit }\end{array}$ \\
\hline T3 & $\begin{array}{l}\text { Inlet water } \\
\text { temparatue }\end{array}$ & F2 & $\begin{array}{l}\text { FuelFlow differential } \\
\text { pressure unit }\end{array}$ \\
\hline T4 & $\begin{array}{l}\text { Outletcal.water } \\
\text { temparature }\end{array}$ & T6 & $\begin{array}{l}\text { Exhaust gas } \\
\text { temparatue after Cal }\end{array}$ \\
\hline T5 & $\begin{array}{l}\text { Exhaust gas } \\
\text { temparatue } \\
\text { before Cal }\end{array}$ & & \\
\hline
\end{tabular}

\section{RESULTS AND DISCUSSIONS}

The engine performance characteristics in terms of brake thermal efficiency (BTE), brake specific fuel consumption (BSFC), brake specific energy consumption (BSEC) and Volumetric efficiency(VE) were estimated through a series of experimental tests. The test results and analysis is presented below.

\subsection{BRAKE THERMAL EFFICIENCY (BTE)}

The variation of BTE for different compression ratios is given in Fig. 3. It has been observed that the BTE of the biodiesel is slightly higher at the compression ratio 17 and lower for low compression ratio. The brake thermal efficiencies increases when the compression ratios from 12 to 17 and then after decreases from 17 to 19 . The result indicates a significant improvement in BTE for biodiesel in variable compression ratio engine.

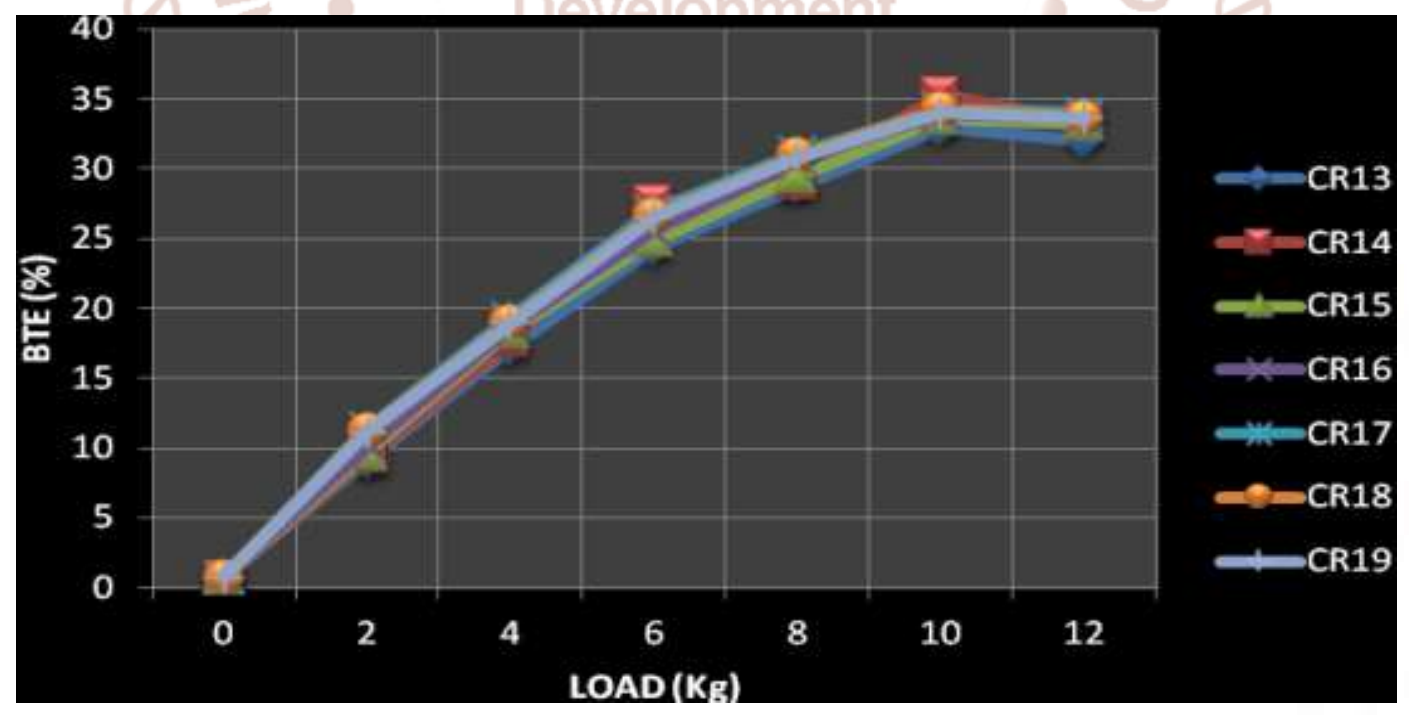

Fig.3 Variation of Brake Thermal Efficiency(BTE) with respect to load.

\subsection{BRAKE SPECIFIC FUELCONSUMPTION (BSFC)}

The brake specific fuel consumption measure of the efficiency of the engine to generate unit power by the unit amount of fuel supplied to the engine. Fig. 4 shows the variations of Brake Specific Fuel Consumption (BSFC) among all compression ratios with engine load at rated speed of $1500 \mathrm{rpm}$. Compression ratio(CR) 17 has lowest BSFC among all Compression Ratios as shown in fig. BSFC decreased with increase of Compression ratio(CR) upto 17. It is also observed that brake specific fuel consumption has decreased with increase of load 
among all compression ratios. At part loads the increase in specific fuel consumption is higher but as the load increases this value decreases and reached to lower at full load condition.

\subsection{BRAKE SPECIFIC ENERGY CONSUMPTION (BSEC)}

The brake specific Energy consumption measure of the efficiency of the engine to generate unit power by the unit amount of Heat energy supplied to the engine. Fig. 5 shows the variations of Brake Specific Energy Consumption (BSEC) for all compression ratios with engine load at rated speed of $1500 \mathrm{rpm}$. Compression ratio(CR) 17 has lowest BSEC among all Compression Ratios as shown in fig. BSEC decreased with increase of Compression ratio(CR) upto 17. It is also observed that brake specific energy consumption has decreased with increase of load among all compression ratios. At part loads the increase in specific energy consumption is higher but as the load increases this value decreases and reached to lower at full load condition.

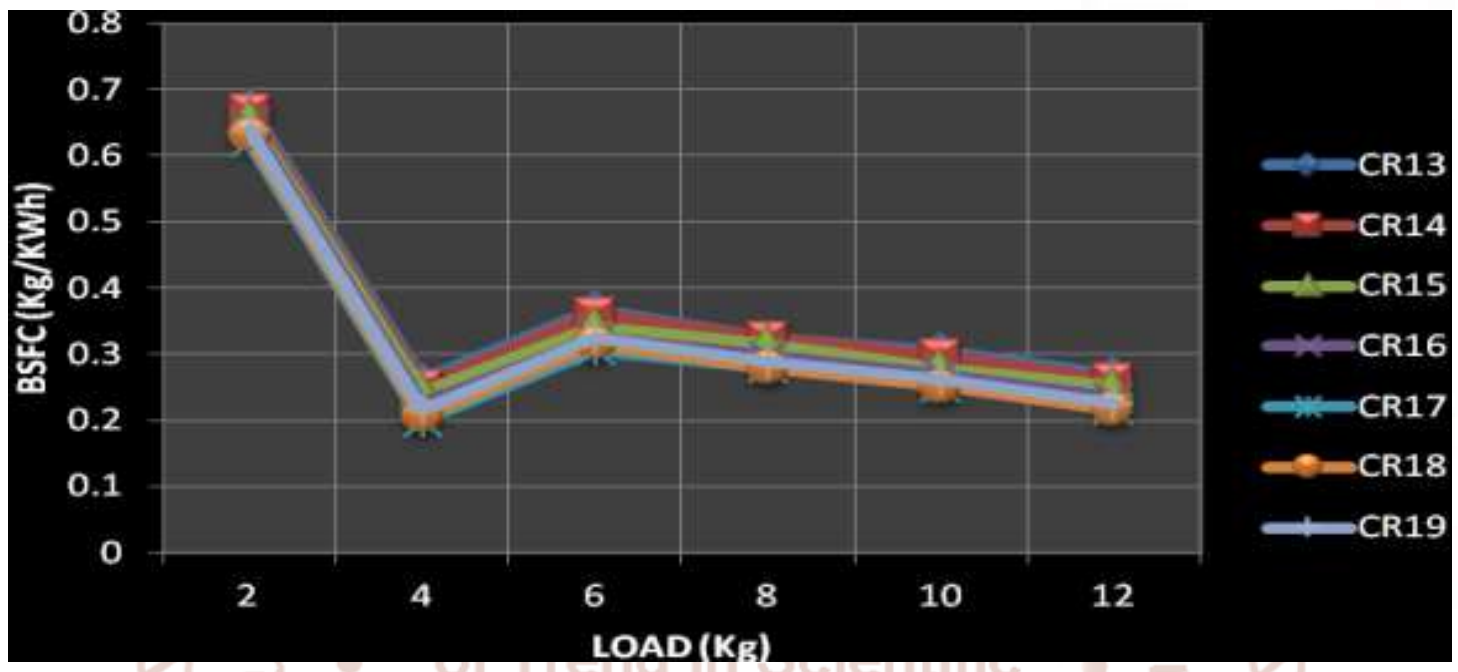

Fig.4 Variation of Brake Specific Fuel Consumption(BSFC) with respect to load.

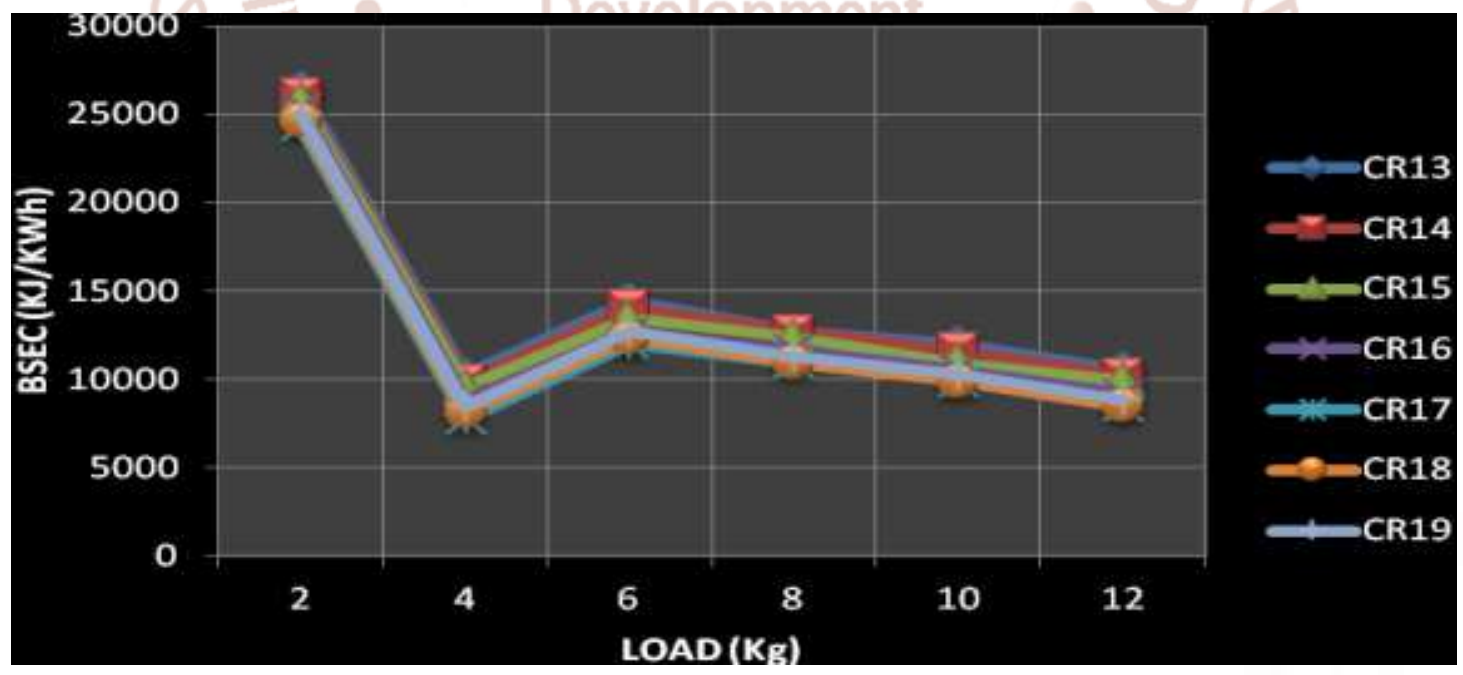

Fig.5. Variation of Brake Specific Energy Consumption(BSEC) with respect to load.

\subsection{VOLUMETRIC EFFICIENCY(VE)}

The variation in volumetric efficiency is comparably less for all range of compression ratio. The reason for increase in volumetric efficiency for maximum compression ratio is due to increase in volume of incoming air to engine. Therefore, the volume occupied inside the engine cylinder is more and, hence, the volumetric efficiency is more for biodiesel. This is shown in Fig. 6. 


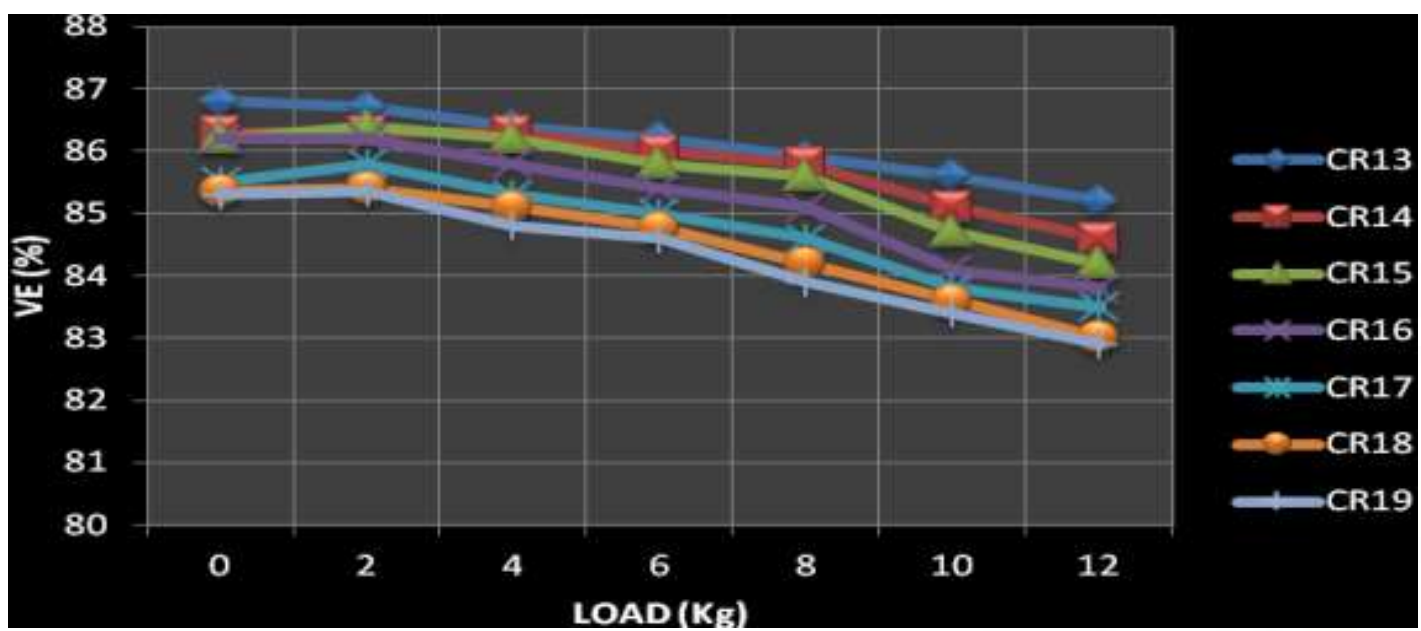

Fig. 6 Variation of volumetric efficiency(VE) with respect to load.

\section{CONCLUSIONS}

The performance of a multi-fuel variable compression ratio engine fueled with esterified Mahua oil have been investigated. The experimental results confirm that the BTE, BSFC, BSEC, and Volumetric efficiency(VE) of variable compression ratio engine are a function of biodiesel, load, and compression ratio. For the similar operating conditions, engine performance reduced for biodiesel. However, by increasing the compression ratio, the engine performance like BSFC, BSEC and brake thermal efficiencies are comparably better in the VCR engine. The following conclusions are drawn from this investigation. The BTE of the esterified Mahua oil in VCR engine is slightly higher at Compression ratio(CR) 17. The BSFC is lower for this condition. This may be due to better combustion, and increase in the energy content of the biodiesel.

\section{REFERENCES}

1) National Biofuel Coordination Committee, National Policy on Biofuels, Government of India, Ministry of New \& Renewable Energy, C.G.O. Complex Lodhi Road, New Delhi- 110003, India

2) Mirzajanzadeh $M$, Tabatabaei $M$, Ardjmand $M$, Rashidi A, Ghobadian B, Barkhi M, "A novel soluble nano-catalysts in diesel biodiesel fuel blends to improve diesel engines performance and reduce exhaust emissions", Fuel, vol. 139, pp. 374-382, 2015.

3) Mohammadi P, Nikbakht AM, Tabatabaei M, Farhadi K, Mohebbi A., "Experimental investigation of performance and emission characteristics of DI diesel engine fueled with polymer waste dissolved in biodiesel-blended diesel fuel,", Energy, vol.46, pp. 596-605, 2012.
4) P. V Rao, K. Vijaya kumar reddy, B. Sudheer Prem Kumar, "Biodiesel: An Introduction", International Journal of Mechanical Engineering and Advanced Automotive Technology Research, Vol..03(2), 2015, pp: 452-457

5) E. Ramjee, K. Vijay Kumar Reddy, and J. Suresh kumar, "Performance and emission characteristics of compression ignition (C.I) engine with dual fuel operation (diesel $+\mathrm{CNG}$ )" journal of petroleum technology and alternative fuels, vol.4(2), pp.24-29, February 2013

6) Agarwal, A.K., and L.M. Das. 2001. Bio diesel development and characterization for use as fuel for diesel engines. Energy Conservation and Management 123:440-7.

7) Arul Mozhi Selvan, V., R.B. Anand, and M. Udayakumar. 2008. Stability, performance and emission characteristics of diesel-ethanol blend with castor oil as additive in variable compression ratio engine. Proceedings of the international conference of Fascinating Advances in Mechanical Engineering-FAME'08. India, December 11-13.

8) Larry, E., J. Stanley, and Mark D. Schrock. 1984. Effect of soybean oil esters on the performance, lubrication oil and water of diesel engines. Society of Automotive Engineers. Paper no. 841385.

9) Schaaf O, Jarvis AP, Van Der Esch SA,et al. 2000. Rapid and sensitive analysis of azadirachtin and related triterpenoids from Neem (Azadirachta indica) by high-performance liquid chromatography-atmospheric pressure chemical ionization mass spectrometry. J Chromat A 886: 89-97. 